LETTER TO JMG

\title{
Severe digital abnormalities in a patient heterozygous for both a novel missense mutation in HOXD 13 and a polyalanine tract expansion in HOXA13
}

\author{
P Debeer, C Bacchelli, P J Scambler, L De Smet, J-P Fryns, F R Goodman
}

J Med Genet 2002;39:852-856

$\mathrm{H}$ ox genes encode a highly conserved family of transcription factors with fundamental roles in body patterning during embryogenesis. ${ }^{1}$ Studies in mouse and chick have shown that the $5^{\prime}$ HoxD and HoxA genes are critical for vertebrate limb and urogenital tract development. ${ }^{2}$ In humans, mutations in HOXD13 and HOXA13 cause the rare dominantly inherited limb malformation syndromes synpolydactyly (SPD, MIM 186000) and hand-foot-genital syndrome (HFGS, MIM 140000), respectively. SPD is characterised by syndactyly between the third and fourth fingers and between the fourth and fifth toes, with variable digit duplication in the syndactylous web. Most cases result from expansions of a polyalanine tract in the $\mathrm{N}$-terminal region of $H O X D 13^{3-6}$ but frameshifting deletions have been identified in three families with an atypical foot phenotype. ${ }^{78}$ HFGS is characterised by short thumbs and halluces, hypospadias in males, Müllerian duct fusion defects in females, and urinary tract malformations in both sexes. Most cases result from nonsense mutations in HOXA13, but two polyalanine tract expansions and one missense mutation have also been described. ${ }^{9-11}$

Here we report two Belgian families, one with the first missense mutation to be identified in HOXD13 and the other with only the third polyalanine tract expansion to be identified in HOXA13. Remarkably, intermarriage between the two families has resulted in a girl heterozygous for both mutations, the first human HOXD13/HOXA13 double heterozygote to be reported. Her digital abnormalities are strikingly more severe than those in carriers of each individual mutation, suggesting that the two mutations act synergistically.

\section{CASE REPORTS}

\section{The proband}

The proband (fig 1) was born with severe bilateral hand abnormalities (fig 2A-F). She had complete cutaneous syndactyly between the third and fourth fingers, duplication of the distal and proximal phalanges of the fourth fingers, and a rudimentary extra central metacarpal. In addition, both thumbs were hypoplastic, with small distal and proximal phalanges and extremely small "angel wing" first metacarpals, and all her fingers were short, with small or absent middle phalanges. In the feet (fig $2 \mathrm{G}, \mathrm{H}$ ), she had short, medially deviated halluces, with small phalanges and first metatarsals. Her remaining toes were also short, with absent middle phalanges. From the age of 3 months, she suffered recurrent urinary tract infections, including one episode of pyelonephritis, but an ultrasound scan of her kidneys and bladder, a DMSA renal scan, and a voiding cystourethrogram showed no abnormalities. She had hypoplastic labia majora and a narrow vaginal introitus, but an ultrasound scan at $2 \frac{1}{2}$ years showed an apparently normal uterus.

\section{Family 1}

The only clinically obvious digital abnormality in the proband's mother (IV.6, family 1, fig 1) was bilateral fifth fin-

\section{Key points}

- Synpolydactyly (SPD) and hand-foot-genital syndrome (HFGS) are rare, dominantly inherited limb malformation syndromes caused by mutations in HOXD13 and HOXA 13, respectively.

- In a four generation SPD family, we have identified the first missense mutation in HOXD13. This mutation, a R31W substitution in the homeodomain, probably destabilises the homeodomain-DNA complex. The digital abnormalities it produces closely resemble those produced by frameshifting deletions in HOXD13, supporting previous suggestions that functional haploinsufficiency for HOXD 13 causes a distinctive phenotype.

- In a three generation HFGS family, we have identified a polyalanine tract expansion in HOXA 13, the third such expansion to be reported.

- A girl heterozygous for both mutations has resulted from intermarriage between the two families. Her digital abnormalities are strikingly more severe than those in carriers of each individual mutation, indicating that the two mutations act synergistically.

- Her phenotype also differs significantly from that of Hoxd $13^{+/} /$Hoxa $13^{+/-}$doubly heterozygous mice, showing that human mutant $H O X$ phenotypes cannot readily be predicted from the corresponding mouse models.

ger clinodactyly (fig 3A). A radiograph of her feet, however (fig 3B), showed small spurs of bone in the first web spaces, representing partial duplication of the bases of the second metatarsals. In addition, the halluces and first metatarsals were unusually broad, the middle phalanges of the second and third toes were hypoplastic, and the middle phalanges of the fourth and fifth toes were fused with the distal phalanges. She was discovered to be a member of a large four generation pedigree with dominantly inherited hand abnormalities (family l, fig 1), part of which has been reported previously. ${ }^{12}$ Fifteen of her relatives also had bilateral fifth finger clinodactyly. Three had in addition been born with mild unilateral SPD, radiologically documented in two cases (III.8 and IV.4) as cutaneous syndactyly between the third and fourth fingers, with a duplicated distal phalanx in the syndactylous web. ${ }^{12}$ One obligate mutation carrier on pedigree analysis (II.2) had normal hands. ${ }^{12}$

\section{Family 2}

The proband's father (III.1, family 2, fig 1) also had bilateral fifth finger clinodactyly. In addition, he had small thumbs with hypoplastic thenar eminences and short first metacarpals, as well as bilateral bony fusion between the scaphoid and 


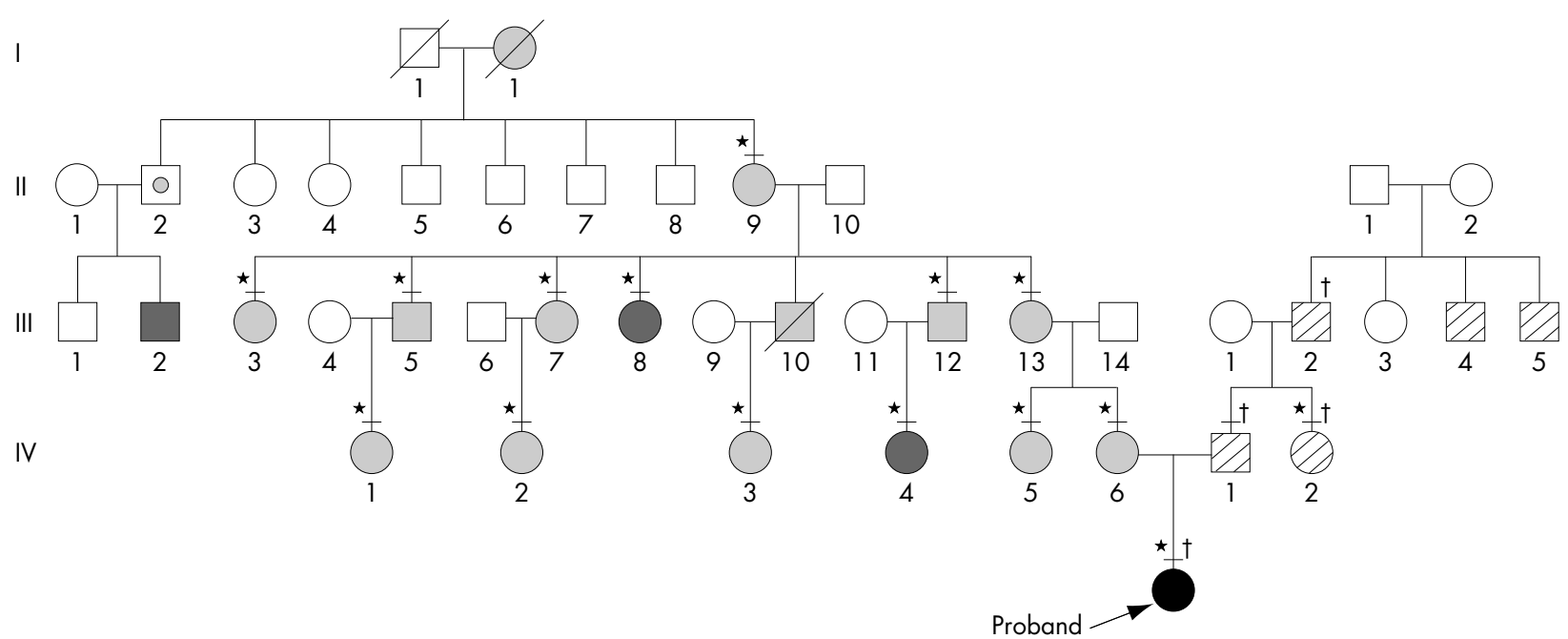

Figure 1 Pedigree of the two families. A horizontal line above a pedigree symbol indicates that the person was examined clinically. In family 1, pale grey symbols represent subjects with bilateral fifth finger clinodactyly only. Dark grey symbols represent subjects who also had SPD in one hand. The dotted symbol indicates a subject who was clinically unaffected but an obligate mutation carrier on pedigree analysis. An asterisk above a pedigree symbol indicates that the person was found on DNA analysis to carry an R3 IW mutation in the homeodomain of HOXD13. In family 2, striped symbols represent people with hand and foot abnormalities typical of HFGS. A dagger above a pedigree symbol indicates that the person was found on DNA analysis to carry a polyalanine expansion in HOXA13.

trapezoid, and fibrous fusion between the scaphoid and trapezium (fig 3C). In the feet (fig 3D), he had small medially deviated halluces with short first metatarsals. The remaining toes were also short, with hypoplastic middle phalanges in the second toes, and fusion between the middle and distal phalanges in the third to fifth toes. Four other members of his family (family 2, fig 1) had similar hand and foot abnormalities. He also had retrograde ejaculation and his sister (III.2) had suffered recurrent urinary tract infections as a child.

\section{METHODS}

Venous blood samples for DNA extraction were obtained from the proband, both parents, 13 other members of family 1 , and two other members of family 2, with their informed consent and the approval of the local research ethics committee. To search for mutations in HOXD13 (GenBank accession numbers AF005219 and AF005220) and HOXA13 (GenBank accession number U82827), the entire coding region of each gene was amplified by PCR in four segments, as described previously. ${ }^{5}$ Amplified fragments were either cycle sequenced directly (Applied Biosystems Prism Dye Terminator Kit) or subcloned into pCRScript (Stratagene) before being cycle sequenced and analysed on an ABI 377 automated sequencer (Applied Biosystems).

\section{RESULTS}

Direct sequencing of HOXD13 in the proband showed a heterozygous $\mathrm{C}$ to $\mathrm{T}$ transition at position 892 of the coding sequence, which converts amino acid 298 (residue 31 of the homeodomain) from arginine to tryptophan. The same base change was identified in the proband's mother and in 12 other affected members of family l (fig l) but not in the proband's father or in 50 unrelated unaffected controls.

PCR amplification of the $5^{\prime}$ portion of exon 1 of HOXA13 in the proband yielded not only a product of the expected size, but also a second larger product, suggesting that she carried a small insertion. Cloning and sequencing of these products showed that she was heterozygous for a $27 \mathrm{bp}$ in frame insertion after base 387 of the coding sequence, within the third of three imperfect trinucleotide repeats encoding polyalanine tracts. This insertion appears to have arisen by duplication of repeats $7-15$, and increases the length of the tract from 18 to 27 residues. The same expansion was identified in her father and in two other affected members of family 2 (fig 1), indicating that it has remained stable in size in this family for at least three generations, but not in the proband's mother.

Direct sequencing of the rest of the coding region of HOXA13 in the proband also showed a heterozygous A to G transition at position 1002. This base change was present in her father, and in II.2 and III.2 from family 2, but not in 50 unrelated unaffected controls. It does not alter an amino acid and is probably just a rare polymorphism (the first to be reported in HOXA13).

\section{DISCUSSION}

\section{R31W substitution in HOXD13}

Homeodomains are highly conserved DNA binding motifs consisting of a flexible N-terminal arm followed by three $\alpha$-helices. ${ }^{13}{ }^{14}$ Residue 31 of the HOXD13 homeodomain lies in the N-terminal part of helix II (fig 4). A comparison of 346 homeodomain proteins shows that $81 \%$, including all invertebrate and vertebrate Hox proteins, have an arginine at this position, while most of the rest have lysine. ${ }^{15-17}$ In the antennapedia, engrailed, and HOXB1 homeodomains, R31 has been found to form a salt bridge with a specific phosphate group in the DNA backbone. ${ }^{13}{ }^{14}{ }^{18} \mathrm{R} 31$ is also predicted to form a salt bridge with a highly conserved glutamate residue at position 42 in helix III. ${ }^{19}$ An R3 IP missense mutation in MSXI, identified in a family with selective tooth agenesis, ${ }^{20}$ results in complete loss of protein activity both in vitro and in vivo. ${ }^{21} \mathrm{An}$ $\mathrm{R} 31 \mathrm{H}$ missense mutation in PITX2, identified in a family with iridogoniodysgenesis syndrome, ${ }^{22}$ reduces the protein's ability to activate transcription in transfection assays by $88 \% .^{23} \mathrm{~A}$ similar R31H missense mutation in MSX2, identified in a family with enlarged parietal foramina, reduces the protein's capacity to bind DNA in gel shift assays by $85 \%$, and results in a phenotype identical to that produced by deletion of the entire MSX2 gene. ${ }^{24}$ Histidine is a basic residue, like arginine, but its weaker positive charge and short ring structure probably impair its ability to make the salt bridges normally formed by R31. Tryptophan, by contrast, is a non-polar and bulky residue. The R31W missense mutation in HOXD13 

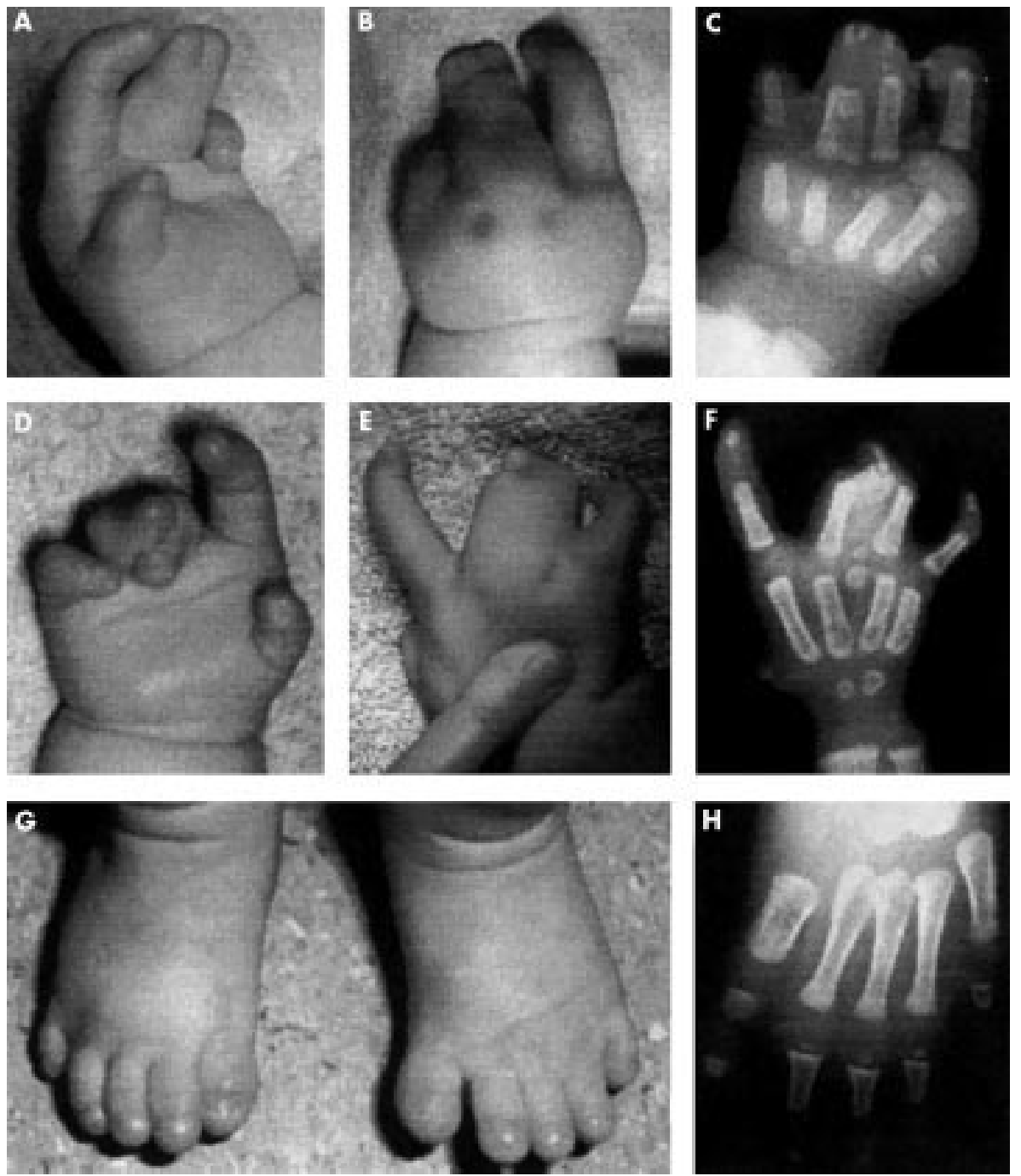

Figure 2 Limb abnormalities in the proband. Photographs of the left hand (A, B) and right hand (D, E) at 6 months, showing syndactyly between the third and fourth fingers, with an extra nail in the syndactylous web on the left, and hypoplastic thumbs. Radiographs of the left hand at 2 days (C) and right hand at 6 months (F), showing duplication of the fourth proximal and distal phalanges, with osseous syndactyly between the duplicated proximal phalanges on the left, a rudimentary extra central metacarpal, hypoplastic first distal and proximal phalanges and first metacarpals, absent middle phalanges in the second, fourth, and fifth fingers, and hypoplastic middle phalanges in the third fingers. (G) Photograph of the feet at 18 months, showing short, medially deviated halluces and small second to fifth toes. (H) Radiograph of the left foot at 16 months, showing small first distal and proximal phalanges and first metatarsal, and absent middle phalanges in the second to fifth toes.

reported here is thus highly likely to destabilise the homeodomain-DNA complex, resulting in complete (or virtually complete) loss of function.

The phenotype produced by this mutation is remarkably mild. Only three of the 17 mutation carriers in family 1 had SPD in the hands, and in all three this was unilateral only, while none had SPD in the feet. Thirteen had just bilateral fifth finger clinodactyly, raising the possibility that some patients with dominantly inherited isolated fifth finger clinodactyly (brachydactyly type A3, MIM 112700) may harbour mutations in HOXD13. Three other probable loss of function mutations in HOXD 13 also cause SPD at low penetrance only. In an Italian family with a frameshifting deletion in exon 1 , only three of the 10 mutation carriers had SPD in the hands and one had SPD in the feet, while in a Scottish family with a frameshifting deletion in exon 2, only two of the 10 mutation carriers had SPD in the hands and seven had SPD in the feet. ${ }^{7}$ In an Italian family with a different frameshifting deletion in exon 2, neither of the two mutation carriers had SPD in the hands or feet. ${ }^{8}$ Mutation carriers in all three families shared a distinctive set of foot abnormalities, however, comprising partial duplication of the second metatarsals, broad halluces, and hypoplasia or symphalangism of the middle phalanges. Exactly the same abnormalities are produced by the missense mutation reported here (fig 3B), confirming previous suggestions that functional haploinsufficiency for HOXD 13 causes a characteristic foot phenotype subtly different from that caused by polyalanine tract expansions. ${ }^{25}$

\section{Polyalanine tract expansion in HOXA13}

The nine alanine expansion in HOXA13 in family 2, like the six and eight alanine expansions reported previously, ${ }^{10}{ }^{11}$ occurs in the third of the protein's three $\mathrm{N}$-terminal polyalanine tracts. Similar pathological expansions have been identified in HOXD13, causing SPD, ${ }^{25}$ as well as in three non-homeodomain transcription factors, CBFAl, ZIC2, and FOXL2, causing cleidocranial dysplasia, holoprosencephaly, and blepharophimosis-ptosis-epicanthus inversus syndrome respectively. ${ }^{26-28}$ In 20 SPD families with different sized expansions, the penetrance and phenotypic severity were found to increase with increasing expansion size. ${ }^{5}$ In the three HFGS families, the phenotype is similar in severity, although III. 2 in 

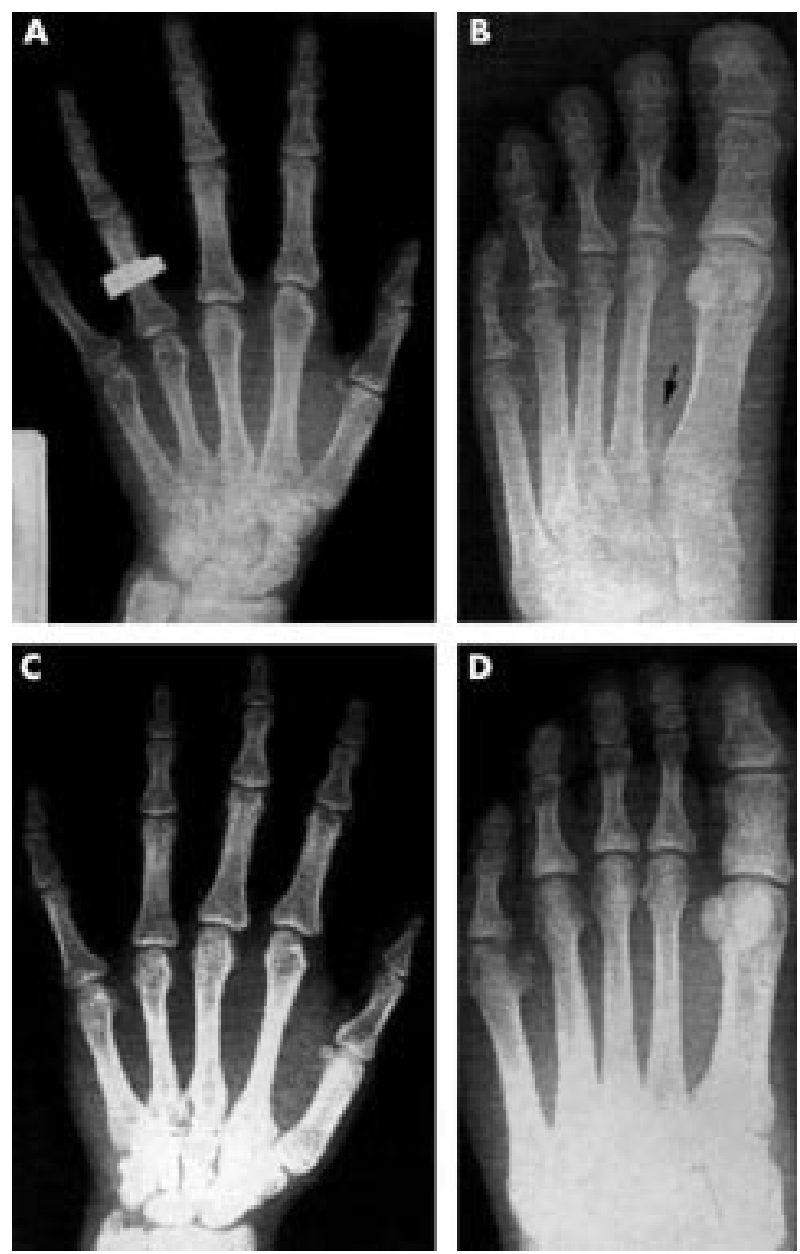

Figure 3 Limb abnormalities in the proband's mother (IV.6, family 1) and father (III. 1, family 2). (A) Radiograph of the mother's left hand at 26 years, showing mild shortening of the fifth middle phalanx. (B) Radiograph of the mother's left foot at 271/2 years, showing partial duplication of the base of the second metatarsal (arrowed), broad first distal and proximal phalanges and first metatarsal, hypoplastic middle phalanges in the second and third toes, and symphalangism of the middle and distal phalanges in the fourth and fifth toes. (C) Radiograph of the father's left hand at 33 years, showing mild shortening of the first metacarpal and fifth middle phalanx, and fusion between the scaphoid and trapezoid, and between the scaphoid and trapezium. (D) Radiograph of the father's left foot at 33 years, showing a short first proximal phalanx and first metatarsal, hypoplastic middle phalanx in the second toe, and symphalangism of the middle and distal phalanges in the third to fifth toes.

family 2 is the first reported HFGS patient with retrograde ejaculation. Recent genetic complementation studies in the synpolydactyly homolog mouse, which carries a short expansion in Hoxd13, have shown that the mutant protein interferes with the function of wild type Hoxd 13 and other 5' Hoxd proteins. ${ }^{29}$ The expansions in HOXA13 that cause HFGS may exert a similar dominant negative effect over the remaining wild type HOXA13, although the phenotype they produce is clinically indistinguishable from that produced by probable

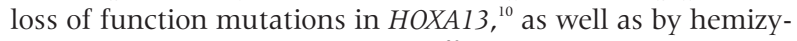
gosity for the entire HOXA13 gene. ${ }^{30}$

\section{Synergistic effects in the double heterozygote}

The proband is heterozygous for both the R31W substitution in HOXD13 and the polyalanine tract expansion in HOXA13. Several features of her phenotype suggest that the two mutations act synergistically. First, the HOXA13 mutation on its own produces only mild shortening of the thumbs (fig 3C) and the

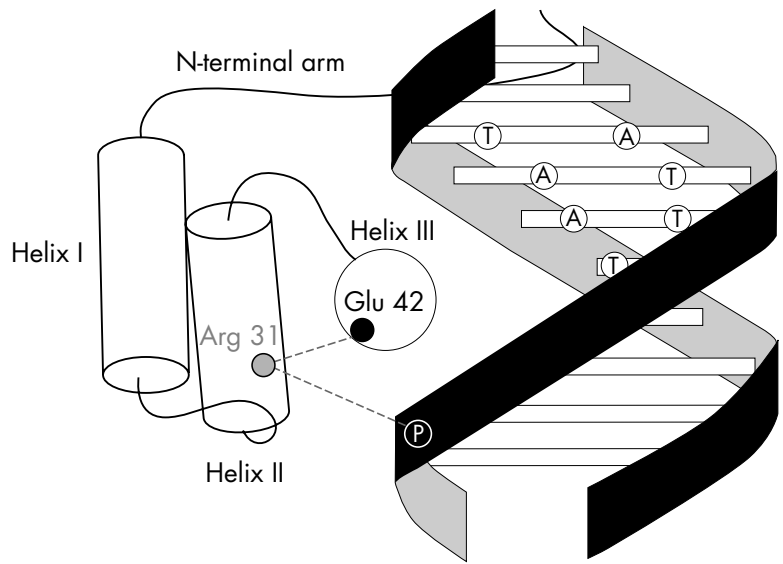

Figure 4 Diagram of typical homeodomain bound to target DNA, showing $\mathrm{N}$-terminal arm followed by three $\alpha$-helices. Helix III contacts specific bases in the major groove of the DNA, while the N-terminal arm contacts bases in the minor groove. Helices I and II lie parallel to each other, across helix III. The side chains of residues in the loop between helices I and II and in the N-terminal part of helix II help stabilise the interaction between the homeodomain and the DNA by contacting phosphate groups in the DNA backbone. The dotted lines indicate the two salt bridges thought to be formed by arginine 31 .

HOXD13 mutation on its own does not affect the thumbs at all (fig 3A), whereas the proband has severely hypoplastic thumbs (fig 2A-F). Studies in mice have shown that Hoxal3 is expressed more strongly than Hoxdl3 in the digit 1 primordium, $^{31}{ }^{32}$ and digit 1 development is particularly affected by loss of Hoxal3 function in both mice ${ }^{32}{ }^{33}$ and humans. ${ }^{90}$ Nevertheless, abnormalities of digit 1 do occur in Hoxd $13^{-}$mice, ${ }^{31}$ as well as in humans heterozygous for specific mutations in $H O X D 13,{ }^{57}$ including shortening of the phalanges and metaphalanges. The proband's HOXD13 mutation may well thus have contributed to her severe thumb hypoplasia.

Second, the HOXD13 mutation on its own produces only unilateral SPD in the hands, with duplication of just the distal phalanges, in three out of 17 mutation carriers in family 1 , whereas the proband has bilateral SPD in the hands, with duplication extending as far proximally as the metacarpals. The HOXA13 mutation on its own does not cause central polydactyly, nor does any other known HOXA13 mutation in either humans ${ }^{910}$ or mice. ${ }^{32}{ }^{33}$ A specific missense mutation in the HOXA13 homeodomain has recently been found to underlie Guttmacher syndrome (MIM 176305), however, in which postaxial polydactyly occurs. ${ }^{34}$ Moreover, loss of one copy of Hoxa 13 causes increased digit number in mice already lacking both copies of Hoxd13. Thus, Hoxd13\% mice have one rudimentary extra postaxial digit in the forelimbs, ${ }^{31}$ but $\mathrm{Hoxal}^{+1} /$

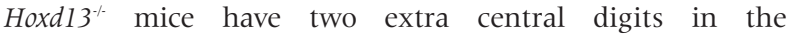
forelimbs. ${ }^{32}{ }^{35}$ The proband's HOXA13 mutation may therefore have contributed to her severe central polydactyly.

Third, each mutation on its own produces shortening of the middle phalanges of the fifth fingers (figs $3 \mathrm{~A}$ and $4 \mathrm{~A}$ ), and shortening or symphalangism of the middle phalanges of the second to fifth toes (figs $3 \mathrm{~B}$ and $4 \mathrm{~B}$ ), whereas the proband has hypoplastic middle phalanges in the third fingers and absent middle phalanges in all her remaining digits (fig 2C, F, H). Middle phalanx hypoplasia/aplasia is also common in mice carrying mutations in individual and multiple 5' Hox genes, including Hoxd13 and Hoxal3. ${ }^{31}{ }^{32}{ }^{36}$ The middle phalanges are the last segments of the digits to form, and their absence is thought to reflect reduced numbers of precursor cells in the undifferentiated mesenchyme of the developing autopod. ${ }^{36}$ Both HOXD13 and HOXA13 thus appear to play important roles in early mesenchymal proliferation. 


\section{Human/mouse differences}

An analysis of the phenotype of Hoxal $3^{+/} / \mathrm{Hoxdl}^{++/}$doubly heterozygous mice also suggests a degree of functional overlap between Hoxal3 and Hoxd $13 .^{32}$ Interestingly, however, the specific abnormalities in these mice differ significantly from those in the proband. Like her, they have shortening of digit 1, soft tissue syndactyly between digits 3 and 4 in the forelimbs, and hypoplasia/aplasia of the middle phalanges in digits 2 and 5. However, unlike her, they also have fusion of the phalanges of digit 1 in the forelimbs, soft tissue syndactyly between digits 2, 3, and 4 in the hindlimbs, and, in about half, an extra postaxial digit in the forelimbs. Unlike her, moreover, they do not exhibit central polydactyly in the forelimbs or absence of virtually all the middle phalanges.

Significant differences also exist between the limb abnormalities in Hoxd13 $3^{+/}$and Hoxal3 $3^{+/}$mice $^{3132}{ }^{36}$ and those in humans heterozygous for probable loss of function mutations in HOXA13 and HOXD13. ${ }^{25}$ These different phenotypes in humans and mice may be explained by subtle differences in the functional effects exerted by the specific targeted and spontaneous mutations in question. They may also reflect differences in genetic background, differences in sensitivity to reduced $\mathrm{HOX} 13$ gene dosage, and/or differences in the roles played by HOXA13 and HOXD 13 in the two species during early autopod development. Whatever the cause, their existence indicates that precise predictions of human mutant HOX phenotypes cannot readily be made from the corresponding mouse models.

\section{ACKNOWLEDGEMENTS}

We are most grateful to the families for participating in our study, as well as to Professor Christine Hall for help in assessing the radiographs. This work was supported by a grant from the Medical Research Council, UK (Clinician Scientist Fellowship to FRG).

\section{Authors' affiliations}

P Debeer, J-P Fryns, Centre for Human Genetics, University of Leuven, Leuven, Belgium

C Bacchelli, P J Scambler, F R Goodman, Molecular Medicine Unit, Institute of Child Health, London, UK

P Debeer, L De Smet, Department of Orthopaedics, University Hospital Pellenberg, Pellenberg, Belgium

Correspondence to: Dr F R Goodman, Room 213, Molecular Medicine Unit, Institute of Child Health, 30 Guilford Street, London WC1N 1EH, UK; fgoodman@hgmp.mrc.ac.uk

\section{REFERENCES}

1 Krumlauf R. Hox genes in vertebrate development. Cell 1994;78:191-201.

2 Zákány J, Duboule D. Hox genes in digit development and evolution. Cell Tissue Res 1999;296:19-25.

3 Muragaki Y, Mundlos S, Upton J, Olsen BR. Altered growth and branching patterns in synpolydactyly caused by mutations in HOXD 13. Science 1996:272:548-51.

4 Akarsu AN, Stoilov I, Yilmaz E, Sayli BS, Sarfarazi M. Genomic structure of HOXD 13 gene: a nine polyalanine duplication causes synpolydactyly in two unrelated families. Hum Mol Genet 1996;5:945-52.

5 Goodman FR, Mundlos S, Muragaki Y, Donnai D, Giovannucci-Uzielli ML, Lapi E, Majewski F, McGaughran J, McKeown C, Reardon W, Upton J, Winter RM, Olsen BR, Scambler PJ. Synpolydactyly phenotypes correlate with size of expansions in HOXD 13 polyalanine tract. Proc Natl Acad Sci USA 1997:94:7458-63.

6 Baffico M, Baldi M, Cassan PD, Costa M, Mantero R, Garani P, Camera G. Synpolydactyly: clinical and molecular studies on four Italian families. Eur J Hum Genet 1997;5(suppl 1): 142

7 Goodman FR, Giovannucci-Uzielli ML, Hall C, Reardon W, Winter R, Scambler P. Deletions in HOXD 13 segregate with an identical, novel foot malformation in two unrelated families. Am J Hum Genet 1998;63:992-1000.

8 Calabrese O, Bigoni S, Gualandi F, Trabanelli C, Camera G, Calzolari E. A new mutation in HOXD13 associated with foot pre-postaxial polydactyly. Eur J Hum Genet 2000;8(suppl 1): 140.

9 Mortlock DP, Innis JW. Mutation of HOXA 13 in hand-foot-genital syndrome. Nat Genet 1997;15:179-80.
10 Goodman FR, Bacchelli C, Brady AF, Brueton LA, Fryns JP, Mortlock DP, Innis JW, Holmes LB, Donnenfeld AE, Feingold M, Beemer FA, Hennekam RC, Scambler PJ. Novel HOXA 13 mutations and the phenotypic spectrum of hand-foot-genital syndrome. Am J Hum Genet 2000;67:197-202.

11 Utsch B, Becker K, Brock D, Lentze M, Bidlingmaier F, Ludwig M. A novel stable polyalanine [poly(A)] expansion in the HOXA13 gene associated with hand-foot-genital syndrome: proper function of poly(A)-harboring transcription factors depends on a critical repeat ength? Hum Genet 2002;110:488-94.

12 De Smet L, Fabry G. Type II syndactyly or synpolydactyly. Acta Orthop Belg 1992;58:209-12.

13 Gehring WJ, Qian YQ, Billeter M, Furukubo-Tokunaga K, Schier AF, Resendez-Perez D, Affolter M, Otting G, Wüthrich K. Homeodomain-DNA recognition. Cell 1994;78:21 1-23.

14 Fraenkel E, Pabo CO. Comparison of X-ray and NMR structures for the Antennapedia homeodomain-DNA complex. Nat Struct Biol 1998;5:692-7.

15 Bürglin TR. In: Duboule D, ed. Guidebook to the homeobox genes. Oxford: Oxford University Press, 1994:25-71.

16 Bürglin TR. Analysis of TALE superclass homeobox genes (MEIS, PBC, KNOX, Iroquois, TGIF) reveals a novel domain conserved between plants and animals. Nucleic Acids Res 1997;25:4173-80.

17 Sharkey M, Graba Y, Scott MP. Hox genes in evolution: protein surfaces and paralog groups. Trends Genet 1997:13:145-51.

18 Piper DE, Batchelor AH, Chang CP, Cleary ML, Wolberger C. Structure of a HoxB 1-Pbxl heterodimer bound to DNA: role of the hexapeptide and a fourth homeodomain helix in complex formation. Cell 1999:96:587-97.

19 Li H, Tejero R, Monleon D, Bassolino-Klimas D, Abate-Shen C, Bruccoler RE, Montelione GT. Homology modeling using simulated annealing of restrained molecular dynamics and conformational search calculations with CONGEN: application in predicting the three-dimensional structure of murine homeodomain Msx-1. Protein Sci 1997;6:956-70.

20 Vastardis H, Karimbux N, Guthua SW, Seidman JG, Seidman CE. A human MSX 1 homeodomain missense mutation causes selective tooth agenesis. Nat Genet 1996;13:417-21.

21 Hu G, Vastardis H, Bendall A, Wang Z, Logan M, Zhang H, Nelson C Stein S, Greenfield N, Seidman CE, Seidman JG, Ábate-Shen C. Haploinsufficiency of MSX 1: a mechanism for selective tooth agenesis. $\mathrm{Mol}$ Cell Biol 1998;18:6044-51.

22 Kulak SC, Kozlowski K, Semina EV, Pearce WG, Walter MA. Mutation in the RIEG 1 gene in patients with iridogoniodysgenesis syndrome. Hum Mol Genet 1998;7:1 113-17.

23 Kozlowski K, Walter MA. Variation in residual PITX2 activity underlie the phenotypic spectrum of anterior segment developmental disorders. Hum Mol Genet 2000:9:2131-9.

24 Wilkie AO, Tang Z, Elanko N, Walsh S, Twigg SR, Hurst JA, Wall SA, Chrzanowska KH, Maxson RE Jr. Functional haploinsufficiency of the human homeobox gene MSX2 causes defects in skull ossification. Nat Genet 2000;24:387-90

25 Goodman FR, Scambler PJ. Human HOX gene mutations. Clin Genet 2001;59:1-11.

26 Mundlos S, Otto F, Mundlos C, Mulliken JB, Aylsworth AS, Albright S, Lindhout D, Cole WG, Henn W, Knoll JHM, Owen M, Mertelsmann R, Zabel BU, Olsen BR. Mutations involving the transcription factor CBFA cause cleidocranial dysplasia. Cell 1997;89:773-9.

27 Brown SA, Warburton D, Brown LY, Yu C, Roeder ER, Stengel-Rutkowski $S$, Hennekam RCM, Muenke M. Holoprosencephaly due to mutations in ZIC2, a homologue of Drosophila odd-paired. Nat Genet 1998;20:180-3.

28 Crisponi L, Deiana $M$, Loi A, Chiappe F, Uda M, Amati P, Bisceglia L, Zelante L, Nagaraja R, Porcu S, Ristaldi MS, Marzella R, Rocchi M, Nicolino M, Lienhardt-Roussie A, Nivelon A, Verloes A, Schlessinger D, Gasparini P, Bonneau D, Cao A, Pilia G. The putative forkhead transcription factor FOXL2 is mutated in blepharophimosis/ptosis/ epicanthus inversus syndrome. Nat Genet 2001;27:159-66

29 Bruneau S, Johnson KR, Yamamoto M, Kuroiwa A, Duboule D. The mouse Hoxd $13^{\text {spdh }}$ mutation, a polyalanine expansion similar to human type II synpolydactyly (SPD), disrupts the function but not the expression of other Hoxd genes. Dev Biol 2001 237:345-53.

30 Devriendt K, Jaeken J, Matthijs G, Van Esch H, Debeer P, Gewillig M Fryns JP. Haploinsufficiency of the HOXA gene cluster, in a patient with hand-foot-genital syndrome, velopharyngeal insufficiency and persistent patent ductus Botalli. Am J Hum Genet 1999;65:249-51.

31 Dollé $\mathbf{P}$, Dierich $A$, LeMeur $M$, Schimmang T, Schuhbaur B, Chambon P, Duboule D. Disruption of the Hoxd13 gene induces localized heterochrony leading to mice with neotenic limbs. Cell 1993;75:431-41.

32 Fromental-Ramain C, Warot X, Messadecq N, LeMeur M, Dollé $P$ Chambon P. Hoxa 13 and Hoxd 13 play a crucial role in the patterning of the limb autopod. Development 1996;122:2997-3011.

33 Mortlock DP, Post LC, Innis JW. The molecular basis of hypodactyly $(H d)$ : a deletion in Hoxa 13 leads to arrest of digital arch formation. Nat Genet 1996;13:284-9.

34 Innis JW, Goodman FR, Bacchelli C, Williams TM, Mortlock DP, Sateesh P, Scambler PJ, McKinnon W, Guttmacher AE. A HOXA13 allele with a missense mutation in the homeobox and a dinucleotide deletion in the promoter underlies Guttmacher syndrome. Hum Mutat 2002;19:573-4.

35 Zákány J, Fromental-Ramain C, Warot X, Duboule D. Regulation of number and size of digits by posterior Hox genes: a dose-dependent mechanism with potential evolutionary implications. Proc Natl Acad Sci USA 1997;94:13695-700.

36 Davis AP, Capecchi MR. A mutational analysis of the 5' HoxD genes: dissection of genetic interactions during limb development in the mouse. Development 1996;122:1 175-85. 